\title{
Avaliação da Tolerância de Cultivares de Soja à Ferrugem Asiática no Oeste da Bahia
}

\author{
Ana C. B. de Oliveira ${ }^{1}$, Cláudia V. Godoy ${ }^{1}$ \& Mônica C. Martins ${ }^{2}$ \\ ${ }^{1}$ Embrapa Soja, Cx. Postal 231, CEP 86001-970, Londrina, PR, fax: (43) 3371-6100, e-mails: \\ barneche@cnpso.embrapa.br, godoy@cnpso.embrapa.br; ${ }^{2}$ Fundação Bahia, CEP 47806-180, \\ Barreiras, BA, fax: (77) 613-8026, e-mail: fundacaoba.soja@aiba.com.br
}

(Aceito para publicação em 04/08/2005)

Autor para correspondência: Cláudia Vieira Godoy

OLIVEIRA, A.C.B., GODOY, C.V. \& MARTINS, M.C. Avaliação da tolerância de cultivares de soja à ferrugem asiática no Oeste da Bahia. Fitopatologia Brasileira 30:658-662. 2005.

\section{RESUMO}

A utilização de tolerância como forma de controle da ferrugem da soja (Glycine max), causada pelo fungo Phakopsora pachyrhizi, pode ser uma alternativa viável, visto que a resistência qualitativa tem-se mostrado instável, em função da variabilidade do fungo. Este trabalho foi realizado na região oeste da Bahia, na safra 2003/04, com objetivo de avaliar a tolerância das principais cultivares de soja utilizadas na região. Foram avaliadas quatro cultivares de ciclo precoce [MG/BR 46 (Conquista), Emgopa 315, BRS Corisco e M-SOY 8411] e quatro cultivares de ciclo tardio (BRS Barreiras, M-SOY 9350, FT 106 e BRS Sambaíba). A tolerância foi quantificada pela diferença de produtividade entre subparcelas tratadas e não tratadas com fungicida. As cultivares MG/BR 46 (Conquista) e M-SOY 8411 apresentaram diferenças de rendimento não significativas, no entanto, essa característica não pôde ser atribuída à tolerância, em função da baixa severidade observada no ensaio. Essa diferença pôde ser atribuída a escape, uma vez que, no momento em que a ferrugem obteve valores mais elevados de severidade, as duas cultivares já estavam na fase final de desenvolvimento. Embora a severidade máxima observada no ensaio tenha sido baixa $30,5 \%$ para a cultivar BRS Barreiras), com exceção das cultivares MG/BR 46 (Conquista) e M-SOY 8411, as demais cultivares avaliadas apresentaram diferença significativa entre as subparcelas tratadas e não tratadas com fungicida, mostrando ausência de tolerância das principais cultivares comerciais cultivadas no oeste da Bahia. Neste trabalho, foi observado que as cultivares de ciclo precoce apresentaram reduções de produtividade inferiores às de ciclo tardio.

Palavras-chave adicionais: resistência, controle, Glycine max.

\begin{abstract}
Tolerance assessment of soybean cultivars to Asian rust caused by Phakopsora pachyrhizi in western Bahia

The use of tolerance as a form of control for soybean rust can be a viable alternative, since qualitative resistance has been shown to be unstable in function of fungal variability. This trial was carried out at in western Bahia in 2003/04, with the objective of assessing the tolerance of the main soybean (Glycine max) cultivars used in the area. Four early maturity cultivars [MG/BR 46 (Conquista), Emgopa 315, BRS Corisco and M-SOY 8411] and four cultivars of late maturity (BRS Barreiras, M-SOY 9350, FT 106 and BRS Sambaíba) were assessed. Tolerance was quantified by determining the difference of yield in subplots treated and untreated with fungicide. The cultivars MG/BR 46 (Conquista) and M-SOY 8411 did not present significant yield differences; however, this could not be attributed to tolerance in function of the low severity observed in this trial. This difference could be attributed to escape, since when the rust obtained higher values of severity, the two cultivars were already in the final stages of development. Although the maximum severity observed in this trial has been low (30.5\% for BRS Barreiras), except MG/BR 46 (Conquista) and MSOY 8411, the others cultivars assessed presented significant differences among the subplots treated and untreated with fungicide. This shows an absence of tolerance in the main cultivars commercially planted in western Bahia. It was observed that early maturity cultivars had inferior yield reductions than late maturity cultivars.
\end{abstract}

Additional keywords: resistance, control, Glycine max.

A ferrugem da soja [Glycine max (L.) Merr.], causada pelo fungo Phakopsora pachyrhizi Syd. \& P. Syd., ocorre no Hemisfério Leste desde 1902, sendo considerada altamente agressiva, causando danos de $10 \%$ a $40 \%$ na Tailândia, $10 \%$ a $90 \%$ na Índia, $10 \%$ a $50 \%$ no sul da China, $23 \%$ a $90 \%$ em Taiwan e $40 \%$ no Japão (Sinclair \& Hartman, 1999). No Brasil, foi relatada pela primeira vez no final da safra de 2000/01 (Yorinori et al., 2002a), representando uma grande ameaça para os países do continente americano. Duas espécies do gênero Phakopsora incidem na cultura da soja (Ono et al., 1992): Phakopsora meibomiae Arthur (Arthur) e P. pachyrhizi. Phakopsora meibomiae foi relatada pela primeira vez no Brasil em 1979, em Minas Gerais, por Deslandes (1979), sendo inicialmente classificada, em função do hospedeiro, como $P$. pachyrhizi. Carvalho Junior \& Figueredo (2000) constataram que, até essa data, a única 
espécie presente no Brasil era $P$. meibomiae, considerada espécie menos agressiva e de ocorrência endêmica, em regiões com temperaturas mais amenas.

A ferrugem causada por $P$. pachyrhizi, também conhecida como ferrugem asiática, foi constatada na região oeste da Bahia, na safra 2002/03, causando perdas estimadas em 400.000 t de soja (Conab, quarto levantamento 2003). Os sintomas iniciais da doença são pequenas pústulas foliares, de coloração castanha a marrom-escura. Na face inferior da folha, pode-se observar uma ou mais urédias que se rompem liberando os uredósporos. As lesões tendem para o formato angular e podem atingir 2 a $5 \mathrm{~mm}$ de diâmetro, podendo aparecer em pecíolos, vagens e caules (Sinclair \& Hartman, 1999). Plantas severamente infetadas apresentam desfolha precoce, comprometendo a formação e o enchimento de vagens e o peso final do grão. Quanto mais cedo ocorrer a desfolha, menor será o tamanho do grão e, conseqüentemente, maior a perda de rendimento e de qualidade (Yang et al., 1991).

A obtenção de cultivar de soja resistente à ferrugem asiática tem sido um desafio para pesquisa. Genes dominantes para resistência, denominados Rppl a $R p p 4$, identificados em introduções de plantas (PI's) e cultivares são relatados na literatura (Bromfield \& Hartwig, 1980; McLean \& Byth, 1980; Hartwig, 1986). No entanto, a estabilidade dessa resistência é duvidosa, devido à grande variabilidade do patógeno. Dezoito raças foram identificadas em amostras coletadas em plantas de soja e hospedeiros selvagens no Japão (Yamaoka et al., 2002). Estudos realizados em Taiwan mostraram a existência de pelo menos uma raça, contendo três genes de virulência (Bromfield, 1981). No Brasil, estudos realizados pela Embrapa Soja identificaram 11 cultivares com resistência à ferrugem (Yorinori et al., 2002b), sendo essa resistência quebrada rapidamente com isolado do fungo proveniente do Mato Grosso. Das quatro fontes de resistência já descritas na literatura, apenas aquelas com os genes Rpp2 e Rpp4 permanecem resistentes à ferrugem no Brasil (Arias et al., 2004).

Outro tipo de resistência a ser explorado é a horizontal, que envolve redução na taxa de desenvolvimento da doença, sendo mais efetiva contra um número maior de raças do patógeno. Entretanto, a quantificação desse modo de resistência é mais difícil, limitando o seu uso (Tschanz \& Wang, 1985). Em função da instabilidade da resistência vertical e das dificuldades associadas com a identificação e a quantificação da resistência horizontal, outros métodos têm sido utilizados objetivando evitar reduções de produtividade com a ferrugem da soja, entre eles o estudo de tolerância de cultivares. Tolerância pode ser definida como a capacidade da planta suportar o desenvolvimento do patógeno, sem apresentar redução significativa na produtividade ou na qualidade do produto (Schafer, 1970). Perdas em produtividade são geralmente utilizadas para avaliar o nível de tolerância e desse modo, quanto menor a perda, maior o nível de tolerância. As perdas podem ser quantificadas pela diferença de produtividade entre parcelas severamente infetadas e parcelas sem doença (Zadocks, 1985). Epidemiologicamente, tolerância e resistência são conceitos diferentes (Vanderplank, 1963), podendo a tolerância ser classificada como uma resistência aparente (Agrios, 1997).

O objetivo deste trabalho foi avaliar as principais cultivares de soja utilizadas no oeste da Bahia, quanto a tolerância à ferrugem asiática da soja.

O ensaio foi conduzido na Fazenda Copacel (rodovia BA 459, km 8, latitude: 1146’31" S, longitude: 46¹3’22"W, altitude: $845 \mathrm{~m}$ ) situada na região das Placas, município de Barreiras, BA. A semeadura foi realizada em 12/11/2003, sendo avaliadas quatro cultivares de ciclo precoce $[\mathrm{MG} / \mathrm{BR}$ 46 (Conquista), Emgopa 315, BRS Corisco e M-SOY 8411] e quatro cultivares de ciclo tardio (BRS Barreiras, M-SOY 9350, FT 106 e BRS Sambaíba).

O delineamento experimental foi blocos ao acaso com parcelas subdivididas, com seis repetições, sendo cada repetição formada por parcelas de quatro linhas, espaçadas de $0,5 \mathrm{~m}$, com $10 \mathrm{~m}$ de comprimento. A parcela continha a cultivar e a subparcela, o tratamento ou não com o fungicida ciproconazole, na dose de $30 \mathrm{~g}$ de ingrediente ativo/ha.

Para diminuir a incidência das doenças de final de ciclo da soja [crestamento foliar de cercospora (Cercospora kikuchii T. Matsu \& Tomoyasu) e mancha parda (Septoria glycines Hemmi)], foi aplicado o fungicida carbendazin (250 $\mathrm{g}$ de ingrediente ativo/ha) em toda área experimental. Os sintomas iniciais de ferrugem foram observados em 6/02/ 2004, quando as cultivares se encontravam entre os estádios R3 e R5, que correspondem ao início de formação das vagens e ao e início de formação da semente, respectivamente (Fehr \& Caviness, 1981).

A aplicação do fungicida para o controle da ferrugem foi realizada logo após constatados os sintomas iniciais no terço inferior das plantas, sendo a primeira aplicação realizada em 7/02/2004, e a segunda em 3/03/2004. As aplicações foram efetuadas com pulverizador costal pressurizado com $\mathrm{CO}_{2}$, com vazão de 200 1/ha e bico leque XR 110.02.

A avaliação da severidade nas parcelas foi realizada com auxílio de escala diagramática, estimando a severidade nos três terços da planta (inferior, médio e superior), de acordo com as normas para avaliação e recomendação de fungicidas para a cultura da soja (Reunião, 2003). Foi avaliada a produtividade nos $5 \mathrm{~m}^{2}$ centrais da parcela, pela quantificação do rendimento $(\mathrm{kg} / \mathrm{ha})$, do peso de cem sementes (PCS) e do número de dias para maturação (NDM). Para verificar a presença de tolerância, foi calculada a diferença de produtividade entre as parcelas tratadas e não tratadas.

As análises estatísticas da severidade foram realizadas por meio do teste de Scott-Knott, a 5\% de significância, para comparação de médias, utilizando o programa SASM-Agri (Canteri et al., 2001). As análises estatísticas de rendimento, número de dias para maturação e PCS foram realizadas por meio do teste de Tukey, a $1 \%$ e $5 \%$ de 
significância, utilizando o programa SAS.

As severidades médias da ferrugem, nas diferentes combinações de cultivares e aplicação de fungicida, podem ser observadas na Tabela 1. A severidade média da ferrugem na cultivar BRS Barreiras sem aplicação do fungicida, evoluiu de 13,3\%, no estádio de vagem formada (R4) (Fehr \& Caviness, 1981), para 30,5\%, quando as vagens apresentavam $50 \%$ dos grãos formados, sendo esse o maior valor de severidade médio estimado nas cultivares não tratadas. Na avaliação da severidade média, na data de 15/ 02/04, os valores ficaram entre $3,8 \%$ a $13,3 \%$, não havendo diferença estatística entre os mesmos, enquanto que, na avaliação do dia 4/3/04, houve a formação de dois agrupamentos pelo teste Skott-Knott. O fungicida ciproconazole foi eficiente no controle da ferrugem, sendo que $5,7 \%$ foi a maior severidade observada nas parcelas tratadas da cultivar MG/BR 46 (Conquista).

Para a variável NDM, apenas as cultivares MG/BR 46 (Conquista) e BRS Corisco apresentaram diferenças significativas entre subparcela tratada e não tratada, evidenciando que, nas condições do experimento, essas cultivares sofreram redução no ciclo da cultura causada pela ferrugem da soja (Tabela 2). Em relação ao PCS, as cultivares: M-SOY 8411, M-SOY 9350 e BRS Sambaíba tiveram diferenças não significativas entre subparcela tratada e não tratada.

As diferenças de rendimento entre as subparcelas tratadas e não tratadas variaram de 304,3 a 1475,5 kg/ha, para as cultivares M-SOY 8411 e BRS Barreiras, correspondendo a perdas de produtividade de $10 \%$ e $39 \%$, respectivamente (Tabela 2). Embora tenham sido observadas diferenças de produtividade não significativas, entre subparcela tratada e não tratada com fungicida, para as

TABELA 1 - Severidade média (\%) da ferrugem (Phakopsora pachyrhizi) nas cultivares de soja (Glycine max) tratadas (T) e não tratadas (NT) com fungicida. Barreiras, BA, 2003/04

\begin{tabular}{lcrr}
\hline \multirow{2}{*}{ Cultivar de soja } & \multirow{2}{*}{ Tratamento } & \multicolumn{2}{c}{ Severidade (\%)* } \\
\cline { 3 - 4 } & & $\mathbf{1 5 / 0 4}$ & $\mathbf{4 / 3} / \mathbf{0 4}$ \\
\hline BRS Barreiras & NT & $13,3 \mathrm{a}$ & $30,5 \mathrm{a}$ \\
MG/BR 46 (Conquista) & NT & $17,8 \mathrm{a}$ & $25,9 \mathrm{a}$ \\
M-SOY 9350 & NT & $11,7 \mathrm{a}$ & $23,6 \mathrm{a}$ \\
BRS Corisco & NT & $12,1 \mathrm{a}$ & $22,6 \mathrm{a}$ \\
BRS Sambaíba & NT & $12,3 \mathrm{a}$ & $20,7 \mathrm{a}$ \\
FT 106 & NT & $9,7 \mathrm{a}$ & $17,9 \mathrm{a}$ \\
EMGOPA 315 & NT & $8,6 \mathrm{a}$ & $17,1 \mathrm{a}$ \\
M-SOY 8411 & NT & $8,0 \mathrm{a}$ & $15,4 \mathrm{a}$ \\
MG/BR 46 (Conquista) & $\mathrm{T}$ & $8,1 \mathrm{a}$ & $5,7 \mathrm{~b}$ \\
BRS Corisco & $\mathrm{T}$ & $7,2 \mathrm{a}$ & $3,3 \mathrm{~b}$ \\
M-SOY 8411 & $\mathrm{T}$ & $4,4 \mathrm{a}$ & $3,1 \mathrm{~b}$ \\
FT 10 6 & $\mathrm{T}$ & $6,5 \mathrm{a}$ & $2,8 \mathrm{~b}$ \\
M-SOY 9350 & $\mathrm{T}$ & $5,1 \mathrm{a}$ & $2,4 \mathrm{~b}$ \\
EMGOPA 315 & $\mathrm{T}$ & $3,9 \mathrm{a}$ & $2,3 \mathrm{~b}$ \\
BRS Sambaíba & $\mathrm{T}$ & $6,2 \mathrm{a}$ & $2,0 \mathrm{~b}$ \\
BRS Barreiras & $\mathrm{T}$ & $3,8 \mathrm{a}$ & $1,8 \mathrm{~b}$ \\
\hline
\end{tabular}

*Médias com mesma letra na coluna não diferem entre si pelo teste de ScottKnott a 5\% de significância. cultivares MG/BR 46 (Conquista) e M-SOY 8411, essa característica não pode ser atribuída à tolerância, em função da baixa severidade observada no ensaio. Essas cultivares apresentam ciclo precoce e, no momento em que a ferrugem obteve valores mais elevados de severidade, já estavam na fase final de desenvolvimento, encontrando-se nos estádios R7 (início da maturação) e R6 (sementes formadas), respectivamente, MG/BR 46 (Conquista) e M-SOY 8411. Isso pode ter sido o fator determinante para que as cultivares tivessem mantido os rendimentos sem diferenças entre subparcelas tratadas e não tratadas. Esse resultado pode ser atribuído a uma reação de evasão ou escape. Assim como a tolerância, o escape pode ser classificado com uma resistência aparente (Agrios, 1997). O escape, como método de controle, baseia-se em táticas de fugas dirigidas contra o patógeno ou contra o ambiente favorável ao desenvolvimento da doença, podendo ser obtida com semeadura em época diferente (Kimati \& Bergamin Filho, 1995). Nas cultivares de ciclo precoce, o fungo tem menos tempo para causar redução de produtividade, em função das mesmas ficarem menos tempo no campo. O mesmo comportamento tem sido observado para doenças de final de ciclo. Cultivares de ciclo tardio apresentam maior intensidade de doenças de final de ciclo, por ficarem mais tempo expostas aos patógenos no campo (Michel et al., 2000). A utilização de cultivares precoces, semeadas no início da época recomendada para cada região, tem sido uma das práticas de manejo recomendadas para evitar redução na produtividade devido à ferrugem. Além do mecanismo de escape das cultivares precoces, devido ao menor tempo de exposição no campo, a ferrugem por ser um patógeno biotrófico, inicia sua multiplicação nas primeiras semeaduras, que servem para a multiplicação inicial do fungo, estando essas semeaduras sujeitas a uma menor pressão de inóculo. Neste trabalho, foi observado que as cultivares de ciclo precoce apresentaram reduções de produtividade inferiores às cultivares de ciclo tardio. Embora a severidade máxima observada no ensaio tenha sido baixa (30,5\% para a cultivar BRS Barreiras), com exceção das cultivares MG/BR 46 (Conquista) e MSOY 8411, as demais apresentaram diferença significativa entre subparcela tratada e não tratada com fungicida, mostrando ausência de tolerância das principais cultivares comerciais cultivadas no oeste da Bahia. Embora não tenha sido observada tolerância nos materiais avaliados, os ensaios devem prosseguir através da analise de tolerância em linhagens, uma vez que a avaliação de tolerância é mais fácil de ser realizada do que resistência. Segundo Tschanz \& Wang (1985), a produtividade pode ser avaliada de modo mais fácil e acurado e relacionada com tolerância, do que a avaliação de severidade relacionada com resistência. Linhagens tolerantes à ferrugem podem ser selecionadas, a partir de populações segregantes se desenvolvendo em condições de ataque severo de ferrugem, simplesmente pela seleção para produtividade. Cultivares tolerantes podem demandar menor número de aplicação de fungicidas e, com isso, reduzir o custo de controle da doença. 
Avaliação da tolerância de cultivares de soja à ferrugem asiática...

TABELA 2 - Rendimento (kg/ha), peso de 100 sementes (PCS), em gramas, e número de dias para maturação (NDM) das cultivares de soja (Glycine max) tratadas (T) e não tratadas (NT) com fungicida e suas respectivas diferenças

\begin{tabular}{|c|c|c|c|c|c|c|c|c|}
\hline \multirow{2}{*}{ Cultivar de soja } & \multirow{2}{*}{ Tratamento } & \multirow{2}{*}{$\mathrm{kg} / \mathrm{ha}$} & \multirow{2}{*}{ PCS } & \multirow{2}{*}{ NDM } & \multirow{2}{*}{ Ciclo } & \multicolumn{3}{|c|}{ Diferença-NT } \\
\hline & & & & & & $\mathrm{kg} / \mathrm{h} \mathrm{a}$ & PCS & NDM \\
\hline MG/BR 46 (Conquista) & NT & 2071 & 15,3 & 113 & $\mathrm{P}$ & $383,4 \mathrm{~ns}$ & $2,6^{* *}$ & $3,0 * *$ \\
\hline MG/BR 46 (Conquista) & $\mathrm{T}$ & 2455 & 17,9 & 116 & $\mathrm{P}$ & & & \\
\hline EMGOPA 315 & NT & 2562 & 13,8 & 124 & $\mathrm{P}$ & $668,0 *$ & $1,6 *$ & $1,7 \mathrm{~ns}$ \\
\hline EMGOPA 315 & $\mathrm{~T}$ & 3230 & 15,4 & 126 & $\mathrm{P}$ & & & \\
\hline BRS Corisco & NT & 2399 & 12,4 & 126 & $\mathrm{P}$ & $752,2 *$ & $1,8 * *$ & $2,3 *$ \\
\hline BRS Corisco & $\mathrm{T}$ & 3151 & 14,3 & 128 & $\mathrm{P}$ & & & \\
\hline M-SOY 8411 & NT & 2859 & 13,4 & 125 & $\mathrm{P}$ & $304,3 \mathrm{~ns}$ & $1,2 \mathrm{~ns}$ & $1,2 \mathrm{~ns}$ \\
\hline M-SOY 8411 & $\mathrm{~T}$ & 3163 & 14,6 & 126 & $\mathrm{P}$ & & & \\
\hline BRS Barreiras & NT & 2249 & 12,4 & 135 & $\mathrm{~T}$ & $1475,5 * *$ & $2,2 * *$ & $1,7 \mathrm{~ns}$ \\
\hline BRS Barreiras & $\mathrm{T}$ & 3725 & 14,6 & 137 & $\mathrm{~T}$ & & & \\
\hline M-SOY 9350 & NT & 2894 & 12,5 & 128 & $\mathrm{~T}$ & $1023,0 * *$ & $0,6 \mathrm{~ns}$ & $2,0 \mathrm{~ns}$ \\
\hline M-SOY 9350 & $\mathrm{~T}$ & 3917 & 13,1 & 130 & $\mathrm{~T}$ & & & \\
\hline FT 106 & NT & 2367 & 11,9 & 129 & $\mathrm{~T}$ & $1196,6 * *$ & $1,9^{* *}$ & $1,3 \mathrm{~ns}$ \\
\hline FT 106 & $\mathrm{~T}$ & 3563 & 13,8 & 130 & $\mathrm{~T}$ & & & \\
\hline BRS Sambaíba & NT & 2461 & 14,1 & 141 & $\mathrm{~T}$ & $1108,7 * *$ & $0,0 \mathrm{~ns}$ & $1,7 \mathrm{~ns}$ \\
\hline BRS Sambaíba & $\mathrm{T}$ & 3569 & 14,1 & 142 & $\mathrm{~T}$ & & & \\
\hline
\end{tabular}

*Significativo a $5 \%$; **Significativo a $1 \%$ pelo teste de Tukey; ns: não significativo

\section{AGRADECIMENTOS} ensaios.

À Fundação Bahia pelo apoio na condução dos

Este artigo foi aprovado para publicação pelo Comitê de Publicações da Embrapa Soja sob o número 27/2004.

\section{REFERÊNCIAS BIBLIOGRÁFICAS}

AGRIOS, G.N. Plant Pathology. 4th ed. California, Academic Press. 1997.

ARIAS, C.A.A., RIBEIRO, A.S., YORINORI, J.T., BROGIN, R.L., OLIVEIRA, M.F. \& TOLEDO, J.F.F. Inheritance of resistance of soybean to rust (Phakospora pachyrhizi Sidow). Anais, VII World soybean research conference, Foz do Iguaçu, PR. 2004. p.100.

BROMFIELD, K.R. \& HARTWIG, E.E. Resistance to soybean rust and mode of inheritance. Crop Science 20:254-255. 1980.

BROMFIELD, K.R. Differential reaction of some soybean accessions to Phakopsora pachyrhizi. Soybean Rust News 4:2. 1981. (Abstract)

CANTERI, M.G., ALTHAUS, R.A., VIRGENS FILHO, J.S., GIGLIOTI, E.A. \& GODOY, C.V. SASM-Agri - Sistema para análise e separação de médias em experimentos agrícolas pelos métodos Scott-Knott, Tukey e Duncan. Revista Brasileira de Agrocomputação 1:18-24. 2001.

CARVALHO JUNIOR, A.A. \& FIGUEREDO, M.B. A verdadeira identidade da ferrugem da soja no Brasil. Summa Phytopathologica 26:197-200. 2000.

CONAB. Previsão e acompanhamento da safra 2002/2003. Quarto levantamento. Abril, 2003. Disponível em: < http:// www.conab.gov.br> Acesso em 22 de outubro de 2004. 16p.

DESLANDES, J.A. Ferrugem da soja e de outras leguminosas causadas por Phakopsora pachyrhizi no Estado de Minas Gerais. Fitopatologia Brasileira 4:337-339. 1979.
FEHR, W.R. \& CAVINESS, C.E. Stage of soybean development. Iowa State University. Special report 80, March, 1981.

HARTWIG, E.E. Identification of a fourth major genes conferring to rust in soybeans. Crop Science 26: 1135-1136. 1986.

KIMATI, H. \& BERGAMIN FILHO, A. Princípios gerais de controle. In: Bergamin Filho, A., Kimati, H. \& Amorim, L. (Eds.) Manual de Fitopatologia. Volume 1: Princípios e conceitos. 3. ed. São Paulo. Editora Agronômica Ceres. 1995. pp.692-709.

McLEAN, R.J. \& BYTH, D.E. Inheritance of resistance to rust (Phakopsora pachyrhizi) in soybeans. Australian Journal Agriculture Research 31:951-956. 1980.

MICHEL, C.A; TOLEDO, H., PEREIRA, M.J.Z. \& PEREIRA, N.M.Z. Reação de genótipos de soja a doenças foliares de final de ciclo. Anais, XXVIII Reunião de Pesquisa de Soja da Região Sul, Santa Maria, RS. 2000. p.116.

ONO, Y., BURITICA, P. \& HENNEN, J.F. Delimitation of Phakopsora, Physopella and Cerotelium and their species on Leguminosae. Mycological Research 96:825-850. 1992.

REUNIÃO DE PESQUISA DE SOJA DA REGIÃO CENTRAL DO BRASIL. Normas para avaliação e recomendação de fungicidas para a cultura da soja. Ata. XXV Reunião de pesquisa de soja da região central do Brasil, Uberaba, MG. 2003. pp.138-146.

SCHAFER, J.F. Tolerance to plant disease. Annual Review of Phytopathology 8:235-252. 1970.

SINCLAIR, J.B. \& HARTMAN, G. L. Soybean rust. In: Hartman, G.L., Sinclair, J.B. \& Rupe, J.C. (Eds.) Compendium of soybean diseases. 4ed. St. Paul. American Phytopathological Society, 1999. pp.3-4.

TSCHANZ, A.T. \& WANG, T.C. Interrelationship between soybean development, resistance, and Phakopsora pachyrhizi. Anais, Fifth International Congress of the Society for the Advanced of Breeding Research in Asia and Oceania, Bangkok, Thailand. 1985. pp.1420.

VANDERPLANK, J.E. Plant diseases: epidemics and control. New 
A.C.B. Oliveira et al.

York. Academic Press. 1963.

YAMAOKA, Y., FUJIWARA, Y., KAKISHIMA, M., KATSUYA, K., YAMADA, K. \& HAGIWARA, H. Pathogenic races of Phakopsora pachyrhizi on soybean and wild host plants collected in Japan. J. Gen. Plant Pathology 68:52-56. 2002.

YANG, X.B., TSCHANZ, A.T., DOWLER, W. M. \& WANG, T.C. Development of yield loss models in relation to reductions of components of soybean infected with Phakopsora pachyrhizi. Journal of Phytopathology 81:1420-1426. 1991.

YORINORI, J.T., PAIVA, W.M., FREDERICK, R.D. \&
FERNANDEZ, P.F.T. Ferrugem da soja (Phakopsora pachyrhizi) no Brasil e no Paraguai, nas safras 2000/01 e 2001/02. Anais, Congresso Brasileiro de Soja, Foz do Iguaçu, PR. 2002a. p.94.

YORINORI, J.T., YORINORI, M.A. \& GODOY, C.V. Seleção de cultivares de soja resistentes à ferrugem "asiática" (Phakopsora pachyrhizi). Anais, XXX Reunião Sul de Soja da Região Sul. Cuz Alta, RS. 2002b. p.94.

ZADOCKS, J.C. On the conceptual basis of crop loss assessment: the threshold theory. Annual Review of Phytopahtology 23:455473. 1985. 